\title{
CITRUS AURANTIFOLIA LEAF EXTRACT AS A POTENTIAL ANTI-CORROSION ADDITIVE IN ALKYD PAINT FOR MILD STEEL
}

\author{
MOHAMMAD FAKHRATUL RIDWAN ZULKIFLI*1', SITI NURSAFINA SHAMSUL BAHRIN ${ }^{1}$, \\ SAMSURI ABDULLAH ${ }^{1}$, MOHD SABRI MOHD GHAZALI ${ }^{2}$ AND WAN MOHD NORSANI \\ WAN NIK ${ }^{1}$
}

${ }^{1}$ Faculty of Ocean Engineering Technology and Informatics, ${ }^{2}$ Faculty of Science and Marine Environment, Universiti Malaysia Terengganu, 21030 Kuala Nerus, Terengganu, Malaysia.

*Corresponding author:fakhratulz@umt.edu.my

Submitted final draft: 20 July $2020 \quad$ Accepted: 26 July 2020

http://doi.org/10.46754/jssm.2021.04.002

\begin{abstract}
Citrus aurantifolia leaf extract (CAL) has been used as an anti-corrosion additive in alkyd paint and tested in $0.2 \mathrm{M} \mathrm{HCl}$. Fourier transform infrared (FTIR) spectroscopy showed several active functional groups and the occurrence of complexation between alkyd paint and CAL extract. Corrosion assessment of the newly modified paint was conducted by weight-loss measurements, electrochemical impedance spectroscopy (EIS) and scanning electron microscope (SEM). Weight-loss percentage was found to decrease as the concentration of CAL extract increased for each week, whereas the effect of the immersion period shows an inverse trend for each concentration. In addition, the Nyquist plot exhibited an increase in the diameter of the semicircle as CAL extract concentrations increased, indicating the coating's resistance towards corrosion. A morphological analysis study using a scanning electron microscope (SEM) confirmed cross-linking between CAL extract and alkyd resin, while several coating defects were observed. Hence CAL extract shows an acceptable potential as anti-corrosion additive in alkyd paint for acidic medium application.
\end{abstract}

Keywords: Citrus Aurantifolia Leaves, anti-corrosion, weight loss measurement, Fourier Transform Infrared Spectroscopy (FTIR), Electrochemical Impedance Spectroscopy (EIS), Scanning Electron Microscope (SEM).

\section{Introduction}

Mild steel is very susceptible to corrosion compared with other metals. However, it is widely used in various applications due to its relatively low price. In practice, most industrial applications, such as refining crude oil, industrial cleaning, petrochemical processes and pipelines use mild steel in the construction of their components (Hussin et al., 2016). During the metallurgy process of mild steel, hydrochloric acid is often used for acid pickling, descaling and other related processes due to economic reasons. Hence it causes severe corrosion to mild steel by the formation of highly soluble ferrous chloride intermediates (Rabizadeh \& Asl, 2019; Dwiyedi et al., 2017; Mohan \& Joseph, 2018; Noor \& AlMoubaraki, 2008; Verma et al., 2018).

In the marine environment, corrosion of metal has been a distinctive problem due to the presence of water, oxygen, and corrosive ionic species. Major sectors, especially oil and gas, face this inevitable problem. However, there are several options to overcome corrosion, and one of them is a corrosion inhibitor. A corrosion inhibitor is a substance or a mixture of substances that is low in concentration, and in an aggressive environment inhibits, prevents, or minimizes the corrosion rate of a metal (Dariya \& Galio, 2014). Currently, the use of natural inhibitors has become a trend as it does not harm humans and the environment.

Citrus aurantifolia has been studied for various applications, and not just for its putative anti-corrosion properties. Çolak, \& Karaköse (2017) had synthesized nanostructured zinc oxide $(\mathrm{ZnO})$ thin film using Citrus aurantifolia (lemon) peel via the spin coating method, with a focus on optoelectronic and electronic applications. A similar study was also conducted by Rafaie et al., (2015), where he examined 
nanostructured $\mathrm{ZnO}$ and magnesium $(\mathrm{Mg})$ dope $\mathrm{ZnO}$ in Citrus aurantifolia via the solgel method for electronic device applications. Meanwhile, Loizzo et al., (2012) studied the chemical composition, antioxidant, and anticholinesterase properties of Citrus aurantifolia peel and leaf extracts to replace the synthetic antioxidants in medication. Boshtam et al., (2011) investigated the antioxidant properties of Citrus aurantifolia (Christm) juice and peel extract on low-density lipoprotein (LDL) oxidation for medications.

In the corrosion field, many studies have been conducted on the inhibitory effects of Citrus aurantifolia. Haldhar et al. (2019) used Citrus aurantifolia leaf extract for corrosion inhibition on mild steel in a $0.5 \mathrm{M}$ sulfuric acid solution using weight loss, Tafel and electrochemical impedance spectroscopy (EIS), where the inhibition efficiency was found to be $96.46 \%$ at $250 \mathrm{mg} / \mathrm{l}$ of the extract concentration. Dakhil et al. (2018) found that an inhibition efficiency of $81.2 \%$ was achieved with $20 \%(\mathrm{v} / \mathrm{v})$ of the extract in $1 \mathrm{M}$ hydrochloric acid for 3 hours immersion at $25^{\circ} \mathrm{C}$ for carbon steel. Hassan et al. (2016) studied the corrosion inhibition effects of Citrus aurantium for mild steel in $1 \mathrm{M}$ of sulphuric acid $\left(\mathrm{H}_{2} \mathrm{SO}_{4}\right)$, and found the maximum inhibition efficiency of $89 \%$ at $40^{\circ} \mathrm{C}$. To the best of our knowledge, no research has been conducted using Citrus aurantifolia leaf extract as an anti-corrosion additive in commercial paint. Thus, Citrus aurantifolia leaves (CAL) extract was opted as a corrosion additive in this study, and the subsequent anti-corrosion effects on mild steel in hydrochloric acid solution are scrutinized.

\section{Materials and Methods}

\section{Sample Preparation}

\section{Preparation of Mild Steel}

Mild steel grade JR235 $(25 \mathrm{~mm} \times 25 \mathrm{~mm} \times$ $4 \mathrm{~mm}$ ) was used in square shape and polished by using a copper brush to remove any loose rust or loose mill scale. The samples were then soaked in thinner and wiped with a wet cloth to remove any oil or dirt from the surface. The mild steel plate was then rinsed with distilled water according to ASTM D 2651 - 01 standards. The samples were stored in a desiccator prior to use.

\section{Preparation of CAL}

Three kilograms of Citrus aurantifolia leaves (CAL) were obtained from a village in Kedah, Malaysia. The leaves were washed and then dried under shade for 10 days in order to enrich the active principles in them (Saratha et al., 2009). CAL was milled using an electric blender, yielding $600 \mathrm{~g}$ of crushed CAL, as shown in Figure 1. The crushed CAL was then soaked in ethanol for a week. The mixture was then put through a BRANSON 5510 sonicator for 15 minutes and repeated three times to integrate the leaves and ethanol. After that, it was filtered by using Whatman No.1 filter paper. A rotary evaporator was used at $60^{\circ} \mathrm{C}$ for the efficient and gentle removal of ethanol from the samples by evaporation.



Figure 1: CAL that was crushed after drying under shade for 10 days

\section{Preparation of Coating}

The incorporation of CAL extract was done according to the formulations in Table 1. The coating mixture was stirred in about an hour for each concentration. A brush was used to apply the coating on the metal surface because it provides very high shearing forces between the liquid paint and the substrate. Equation 1 was used to determine the concentration of CAL extract. 
Table 1: Coating formulation for the concentration of CAL extract.

\begin{tabular}{ccc}
\hline CAL extract $(\mathbf{m l})$ & Alkyd paint $(\mathbf{m l})$ & Concentration of CAL $(\mathbf{v} / \mathbf{v} \%)$ \\
\hline Control & 66 & 0.00 \\
0.2 & 66 & 0.30 \\
0.3 & 66 & 0.45 \\
0.4 & 66 & 0.60 \\
\hline
\end{tabular}

Concentration $(\%)(v / v)=\frac{\text { soluble }(\mathrm{ml})}{\text { solvent }(\mathrm{ml})} \times 100($ Eq. 1)

\section{Fourier Transform Infrared (FTIR)}

Fourier transform infrared (FTIR) was carried out using a Thermo Nicolet 380 FTIR Spectrometer. The spectrometer was used to identify the functional group of CAL by observing the vibrational motion of bonds in molecules. The subsequent effect after the incorporation was studied as well. This spectrometer is equipped with an Attenuated Total Reflection (ATR) accessory with a germanium crystal. The sample was placed on a germanium crystal, and infrared light was passed through the sample with the frequency ranging from 3960 to $660 \mathrm{~cm}^{-1}$, with the spectral resolution of $4 \mathrm{~cm}^{-1}$ (Samsudin et al., 2012). The FTIR data were recorded in the transmittance mode. The transmittance and reflectance of the infrared rays at different frequencies were translated into an IR absorption plot consisting of reverse peaks. The spectral pattern was analysed and matched according to the IR absorption table.

\section{Immersion Process}

Mild steel specimens were hung and fully immersed in an aquarium filled with 14 litres of $0.2 \mathrm{M} \mathrm{HCl}$ solution. The immersion period was five weeks, with data collection done every week.

\section{Weight Measurement Method}

The initial and final weight of the mild steel samples were measured to calculate percentage of weight loss. Before the coated samples were immersed in the $\mathrm{HCl}$ solution, the initial weight of the samples was measured by using an analytical balance. Mild steel coupons (JR 235) were taken out every week from the aquarium and were dried at room temperature before being weighed. Equation 2 was used to determine the percentage of weight loss:

$$
\% \text { Weight loss }=\frac{\text { Weight }_{\text {initial }}-\text { Weight }_{\text {fnal }}}{\text { Weight }_{\text {initial }}} \times 100
$$

\section{Electrochemical Impedance Spectroscopy (EIS)}

EIS was used to study the impedance characteristic as well as the capacitance behaviour of the coated mild steel samples in the presence and absence of CAL. The EIS measurement was conducted by using alternating current (AC) signal of impedance measurements by using the Autolab PGSTAT302N with respect to the open circuit potential (OCP). All the potentials referred were relative to a saturated calomel electrode (SCE). The impedance measurements were conducted in triple trials over a frequency range of 10000 $\mathrm{Hz}$ down to $0.01 \mathrm{~Hz}$. The results were analysed using the NOVA 1.10 electrochemical program.

\section{Scanning Electron Microscope (SEM)}

Scanning electron microscope (SEM) model JEOL JSM-6360LA was used in this study to observe and analyse the morphology of the coated mild steel. The samples were coated with an ultrathin gold particle layer using a JFC-1600 Auto Fine Coater (JEOL Ltd., Tokyo, Japan). The gold-coated samples were electrically conductive to allow the scanning process on the sample surface at the accelerated voltage of 15 $\mathrm{kV}$ and the working distance of $10 \mathrm{~mm}$. 


\section{Results and Discussion}

\section{Fourier Transform Infrared (FTIR)}

Figure 2 shows the molecular structure of the phenolic compound and alkyd resin monomer. CAL extract is represented by phenolic compound because the most effective compound of CAL is phenolic compounds (Hassan et al., 2016). The absorption band of CAL, alkyd undercoat, Alkyd $+0.30 \%$ CAL, Alkyd $+0.45 \%$ CAL and Alkyd $+0.60 \%$ CAL is tabulated in Table 2. CAL extract shows few distinctive features in its absorption band. The peak at $3382 \mathrm{~cm}^{-1}$ shows a hydroxyl functional group $(\mathrm{OH})$ of carboxylic acid. A medium absorption band was found at $1629 \mathrm{~cm}^{-1}$ indicating the presence of the $\mathrm{C}=\mathrm{C}$ alkene group while $-\mathrm{C}-\mathrm{H}$ (bending) can be found at $1444 \mathrm{~cm}^{-1}$ absorption band, where similar peaks for CAL extract were reported elsewhere (Velasco et al., 2017). A stretching vibration of $\mathrm{C}-\mathrm{O}$ was exhibited by the strong absorption peak at $1064 \mathrm{~cm}^{-1}$, and $=\mathrm{C}-\mathrm{H}$ (bending) was observed at $868 \mathrm{~cm}^{-1}$.

Meanwhile, alkyd undercoat shows a stretching vibration of $\mathrm{OH}$ at $3364 \mathrm{~cm}^{-1}, \mathrm{C}-\mathrm{H}$ aliphatic stretching vibration at 2919 and 2815 $\mathrm{cm}^{-1}, \mathrm{C}=\mathrm{O}$ of ester at $1738 \mathrm{~cm}^{-1}$, asymmetric bending of a methyl group at $1420 \mathrm{~cm}^{-1}$, a strong band of the unsaturated ring at $1079 \mathrm{~cm}^{-1}$ and out of plane aromatic $\mathrm{C}-\mathrm{H}$ bending vibration at 712 $\mathrm{cm}^{-1}$. The interpretation of the alkyd undercoat FTIR absorption band is tabulated in Table 2 .

Upon incorporation of CAL extract into the alkyd paint, the band shifted to $1726 \mathrm{~cm}^{-1}$ from its original band at $1738 \mathrm{~cm}^{-1}$ for all concentrations. A shifting of aromatics and $\mathrm{C}=\mathrm{O}$ compounds upon addition of CAL extract shows the dissociation of alkyd resin polymer backbone while CAL extract has been associated with the polymer to form a complexation (Zulkifli et al., 2020).

In addition, the aliphatic stretching vibration of alkyd undercoat at $2851 \mathrm{~cm}^{-1}$ also shifted to $2858 \mathrm{~cm}^{-1}$ upon the incorporation of CAL extract. The reduction of the intensity indicates dissociation of the polymer chain. Incorporation of CAL extract into the alkyd paint has caused the formation of a new strong absorption band at $1265 \mathrm{~cm}^{-1}$. This band is associated with a new stretching vibration of $\mathrm{C}-\mathrm{O}-\mathrm{C}$ that is attached to the aliphatic or aromatic moiety in alkyd undercoat. This indicates the formation of hydrogen bonding with the phenolic group of CAL extract. The same cross-linked spectrum trend has been reported elsewhere (Dhoke et al., 2008).
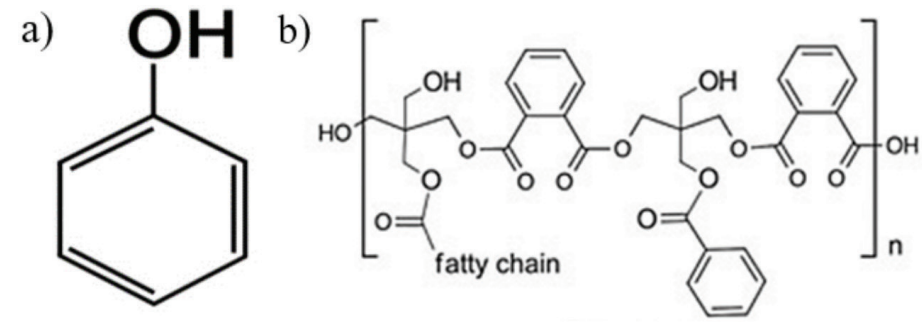

Figure 2: Molecular structure of a) phenolic compound and b) alkyd resin (Hassan et al., 2016; Sonnati et al., 2012) 
Table 2: Interpretation of absorption bands of CAL, alkyd undercoat and alkyd incorporated with $0.30 \%$, $0.45 \%$ and $0.60 \%$ of CAL extract.

\begin{tabular}{|c|c|c|c|c|c|c|c|c|}
\hline Sample & \multicolumn{7}{|c|}{ Wavenumber $\left(\mathrm{cm}^{-1}\right)$} & Validation \\
\hline & 2924 & 1629 & 1444 & 1064 & 868 & & & \multirow[b]{2}{*}{$\begin{array}{l}\text { Siti et al., } \\
2017\end{array}$} \\
\hline $\begin{array}{l}\text { CAL } \\
\text { extract }\end{array}$ & $\begin{array}{c}\mathrm{OH} \\
\text { carboxylic } \\
\text { acid }\end{array}$ & $\begin{array}{l}\mathrm{C}=\mathrm{C} \\
\text { alkene } \\
\text { group }\end{array}$ & $\begin{array}{c}-\mathrm{C}-\mathrm{H} \\
\text { (bending) }\end{array}$ & $\mathrm{C}-\mathrm{O}$ & $\begin{array}{c}=\mathrm{C}-\mathrm{H} \\
\text { (bending) }\end{array}$ & & & \\
\hline & 3364 & 2919 & 2815 & 1738 & 1420 & 1079 & 712 & \multirow[b]{2}{*}{$\begin{array}{c}\text { Elba } \text { et al., } \\
2018\end{array}$} \\
\hline $\begin{array}{c}\text { Alkyd } \\
\text { undercoat }\end{array}$ & $\begin{array}{c}\mathrm{OH} \\
\text { stretching } \\
\text { vibration }\end{array}$ & \multicolumn{2}{|c|}{$\begin{array}{c}\text { C-H aliphatic } \\
\text { stretching vibration }\end{array}$} & $\begin{array}{l}\mathrm{C}=\mathrm{O} \\
\text { ester }\end{array}$ & $\begin{array}{c}\text { Symmetric } \\
\text { bending of } \\
\text { a methyl } \\
\text { group }\end{array}$ & $\begin{array}{c}\text { Strong } \\
\text { unsaturated } \\
\text { ring }\end{array}$ & $\begin{array}{l}\text { Out of } \\
\text { plane } \\
\text { aromatic } \\
\text { C-H } \\
\text { bending } \\
\text { vibration }\end{array}$ & \\
\hline $\begin{array}{c}\text { Alkyd + } \\
0.30 \% \\
\text { CAL }\end{array}$ & 3398 & 2922 & 2858 & 1726 & 1450 & 1265 & & \multirow{4}{*}{$\begin{array}{l}\text { Dhoke et } \\
\text { al., } 2008\end{array}$} \\
\hline $\begin{array}{c}\text { Alkyd + } \\
0.45 \% \\
\text { CAL } \\
\end{array}$ & 3385 & 2922 & 2856 & 1726 & 1452 & 1265 & & \\
\hline $\begin{array}{c}\text { Alkyd + } \\
0.60 \% \\
\text { CAL }\end{array}$ & 3385 & 2922 & 2858 & 1726 & 1448 & 1265 & & \\
\hline & $\begin{array}{c}\mathrm{OH} \\
\text { stretching } \\
\text { vibration } \\
\text { (from } \\
\text { alkyd } \\
\text { undercoat) }\end{array}$ & \multicolumn{2}{|c|}{$\begin{array}{c}\mathrm{C}-\mathrm{H} \text { aliphatic } \\
\text { stretching vibration }\end{array}$} & $\begin{array}{c}\mathrm{C}=\mathrm{O} \\
\text { stretch } \\
\text { (from } \\
\text { alkyd) }\end{array}$ & $\begin{array}{c}\text { Symmetric } \\
\text { bending of } \\
\text { a methyl } \\
\text { group }\end{array}$ & $\begin{array}{c}\text { C-O-C } \\
\text { stretching } \\
\text { vibrations } \\
\text { attached } \\
\text { with an } \\
\text { aliphatic } \\
\text { and } \\
\text { aromatic } \\
\text { moiety }\end{array}$ & & \\
\hline
\end{tabular}

\section{Weight Measurement}

Weight measurement is one of the reliable methods to investigate the behaviour of metallic structures in corrosive media (Masroor et al., 2017). Figure 3 shows the percentage of weight loss for all coated samples. Across the first week of immersion, it can be observed that coated mild steel without incorporation of CAL extract shows the highest weight loss percentage (4.4\%) while the incorporation of CAL extract reduced weight-loss percentage to $4.1 \%(0.30 \%), 3.2 \%$ $(0.45 \%)$ and $3.2 \%(0.60 \%)$ respectively. As the immersion period increases, weight loss percentage also increased, and after the third week, the percentage dropped slightly and plateaued afterwards. This could be due to the rust, which is the by-product of the corrosion process, accumulating on the steel surface. For coated samples without any CAL extract loading, weight-loss percentage increased from $4.4 \%$ to $4.6 \%$ as the immersion period progressed from week 1 to week 5, indicating the increment of corrosion activity and destruction of the coating layer. Note that there is a hike of weight-loss percentage at week 3 , which could be due to the 
deposition of corrosion products that impede further corrosion activity. The incorporation of CAL extract also shows the same trend as the coated samples without CAL extract loading. However, as the immersion period increases, the difference in weight-loss percentage between $0 \%$ of CAL extract with $0.3 \%, 0.45 \%$ and $0.6 \%$ becomes smaller. This is due to the corrosion activity caused by permeation of moisture through the coating defect-like void, or capillaries (Sung et al., 2017). Water permeation occurs when moisture enters the pores and is drawn by any polar function groups within the coating. As discussed in the FTIR section, the addition of CAL extract has dissociated
$\mathrm{OH}$ functional groups, which limits the water permeation into the alkyd coating.

Also, the increment of weight-loss percentage across the immersion period, as seen in Table 3, could be due to coating defects. Coating defects caused by free spaces left by solvent evaporation open a path for water molecules to enter the coating. Due to the small size of its molecules, water can easily penetrate and fill these free spaces in the coating until it reaches the metal surface. Once the metal is in contact with water, corrosion activity starts and results in more coating defects, like swelling and delamination (Othman et al., 2006).

Table 3: Weight loss percentage and coating efficiency of coated samples for five weeks immersion period.

\begin{tabular}{ccc}
\hline Type of Sample & Period & $\begin{array}{c}\text { Weight Loss } \\
\text { Percentage (\%) }\end{array}$ \\
\hline \multirow{2}{*}{$0.00 \%$} & Week 1 & 4.4 \\
& Week 2 & 4.5 \\
& Week 3 & 5.1 \\
& Week 4 & 4.8 \\
Week 5 & 4.6 \\
\hline \multirow{2}{*}{$0.30 \%$} & Week 1 & 4.1 \\
& Week 2 & 4.3 \\
& Week 3 & 4.8 \\
& Week 4 & 4.6 \\
& Week 5 & 4.6 \\
\hline \multirow{2}{*}{$0.45 \%$} & Week 1 & 3.2 \\
& Week 2 & 3.6 \\
& Week 3 & 4.6 \\
& Week 4 & 4.5 \\
& Week 5 & 4.3 \\
\hline & Week 1 & 3.2 \\
& Week 2 & 3.3 \\
& Week 3 & 4.2 \\
& Week 4 & 4.2 \\
& Week 5 & 4.1 \\
\hline & & \\
& &
\end{tabular}






Figure 3: Graph of percentage of weight loss (\%) against the immersion period (weeks)

Electrochemical Impedance Spectroscopy (EIS)

The impedance plot in Figure 4 shows a single non-perfect capacitive semicircle, which is attributed to the charge-transfer process at the electrode-electrolyte interphase. The nonperfect semicircle is attributed to the surface heterogeneity caused by surface roughness as well as uneven coating coverage (Ahamad \& Quraishi, 2010). It is obvious that as the CAL extract concentration increases, the diameter of the semicircle also increases.

EIS was conducted at week three of immersion, as this period showed the greatest efficiency according to the weight measurement results. The Nyquist plot in Figure 4 represents the impedance spectra of alkyd paint in the absence and presence of CAL extract. An electrochemical circle fit was used to determine the electrochemical parameters, and the corresponding values are tabulated in Table 4. All samples showed a one-time constant,

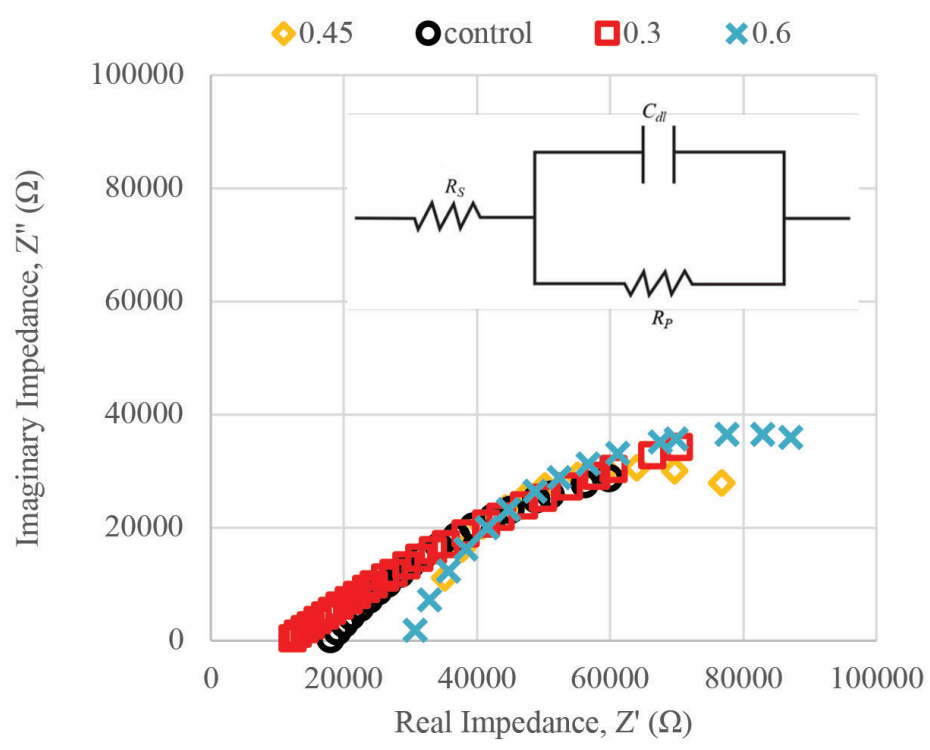

Figure 4: Nyquist plot and equivalent circuit of mild steel in $\mathrm{HCl}$ solution with and without CAL loading in alkyd undercoat after week 3 
represented by one semicircle plot. The solution resistance $\left(R_{\mathrm{s}}\right)$ for all tested samples was found to vary. This could be due to non-uniform current distribution through a definite electrolyte area. Eventually, it will cause a non-steady state condition, which might have resulted from the changes of the electrochemical cell through adsorption of solution impurities, growth of an oxide layer, the build-up of reaction products in solution, to name a few (Instruments, 2007). Polarization resistance $\left(R_{p}\right)$ was found to increase upon the incorporation of CAL extract. $R_{p}$ increased from $6.26 \times 10^{4}$ for coating without $\mathrm{C}^{p}$ AL loading to $1.08 \times 10^{5}, 1.21 \times 10^{5}$ and $2.57 \times$ $10^{5} \Omega$ for coating with $0.30 \%, 0.45 \%$ and $0.60 \%$ CAL loading, respectively. The increment of $R_{p}$ indicates a better impedance behaviour of the coating towards corrosion where less water uptake occurred. As CAL extract was loaded into the alkyd paint matrix, double-layer capacitance value $\left(C_{d l}\right)$ decreased from $1.01 \times 10^{-5}$ to $1.03 \times$ $10^{-5}, 1.06 \times 10^{-5}$ and $6.19 \times 10^{-6} \mathrm{~F}$ with regards to coating with $0 \%, 0.30 \%, 0.45 \%$ and $0.60 \% \mathrm{CAL}$ loading respectively indicating a low absorption of moisture into the coated substrate. This value also represents the water barrier property of the coating. In addition, it has been reported that a larger $R_{p}$ was associated with a slow corroding system and improved additive protection, which eventually decreases the value of the metal capacitance, $C_{d l}$ (Al-Amiery et al., 2014). The equivalent circuit for the coating system, as shown in Figure 4 is composed of the solution resistance $\left(R_{s}\right)$, polarization resistance $\left(R_{p}\right)$ and double-layer capacitance $\left(C_{d l}\right)$. A similar equivalent circuit for the alkyd coating system has also been demonstrated elsewhere (Deyab, 2015).

\section{Scanning Electron Microscope (SEM)}

Micrographs of SEM and camera image for uncoated, coated and coated with CAL extract samples are shown in Table 5. For uncoated mild steel, the camera image shows discoloration where corrosion products are deposited. The dark area in the SEM image indicates the existence of pores surrounded by multiple layers of corrosion product, which is represented by fairer flakes. The deposition of corrosion products like rust will establish an osmotic driving force, which consequently enhances water permeability. Multiple layers of alkyd resin polymer with micropores and capillary can be found in the coated sample without the incorporation of CAL extract. The camera image shows coating delamination as well as corrosion product at the edge of the sample. A darker colour on the surface of the SEM image indicates a void and micropores that causes the penetration of moisture to the metal surface (Tator \& Lanterman, 2016). A coated sample with $0.30 \%$ CAL extract shows an occurrence of microcrack or capillary. The camera image shows the existence of pores and corrosion products on the metal surface. There is an accumulation of CAL cross-linked with alkyd coating represented by fairer softedged flakes. There is also an area with low cross-linked density providing an open path for moisture penetration. As the concentration of CAL extract increases, the cross-linked area becomes more uniform and having fewer low cross-linked density areas, as seen in the coated sample with $0.30 \%$ of CAL extract. Formation of a close pack structure with a low density of microcracks and capillaries were observed, which consequently enhances the anti-corrosion property of the modified coating.

Table 4: $R_{p}$ and $C_{d l}$ of mild steel JR235 in $\mathrm{HCl}$ solution obtained by using the impedance method for week 3

\begin{tabular}{ccc}
\hline CAL Concentration (\%) & $(\Omega)$ & $(\mathbf{F})$ \\
\hline 0.00 & $6.26 \times 10^{4}$ & $1.01 \times 10^{-5}$ \\
0.30 & $1.08 \times 10^{5}$ & $1.03 \times 10^{-5}$ \\
0.45 & $1.21 \times 10^{5}$ & $1.06 \times 10^{-5}$ \\
0.60 & $2.57 \times 10^{5}$ & $6.19 \times 10^{-6}$ \\
\hline
\end{tabular}


Table 5: SEM and camera images after 5 weeks of immersion period

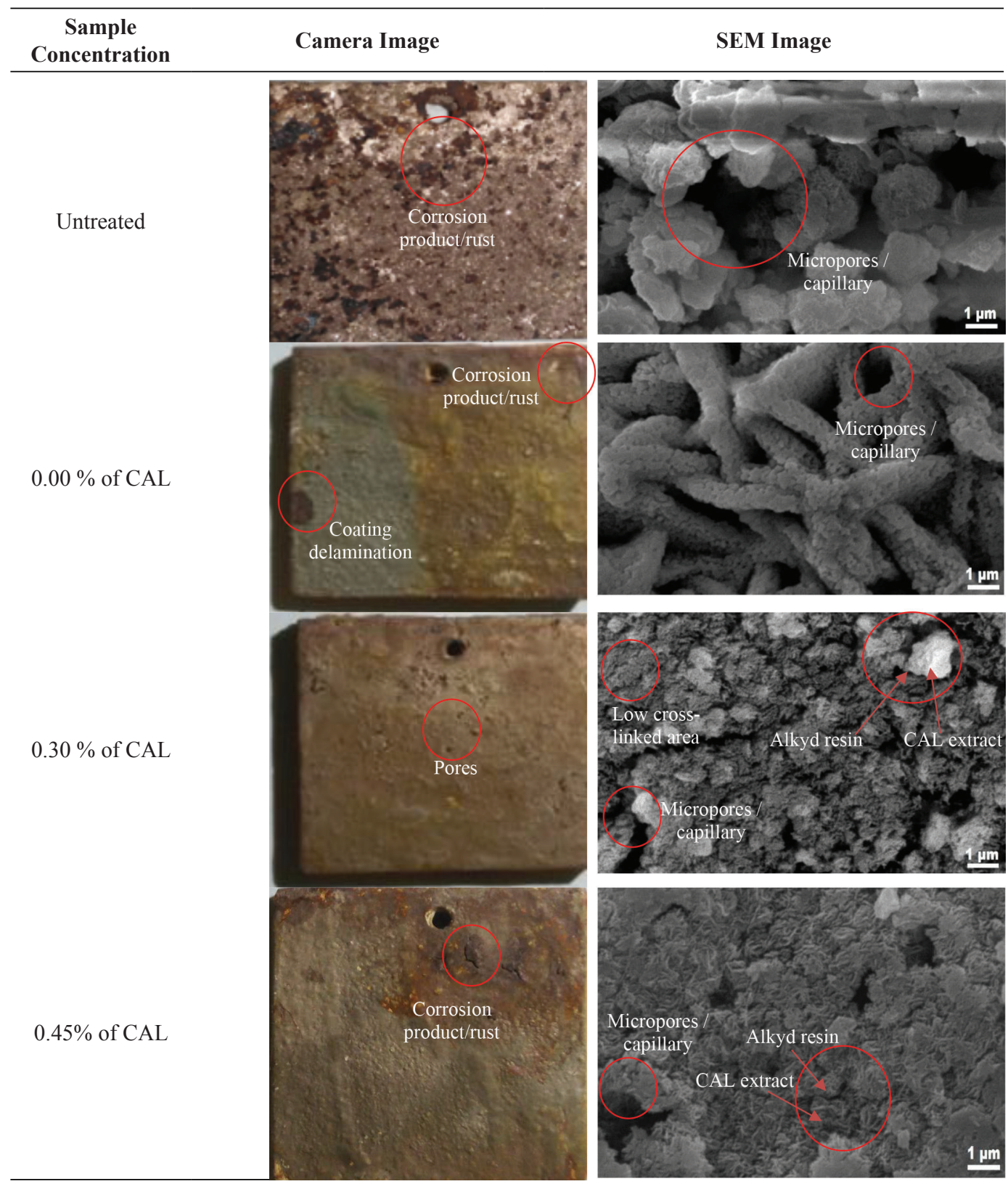

\section{Conclusion}

Extracts from Citrus Aurantifolia leaves (CAL) were used as an anti-corrosion additive in alkyd undercoat. In general, CAL extract exhibits an acceptable potential as an anti-corrosion additive in alkyd coating for acidic medium.
FTIR analysis of CAL shows the presence of aromatic, hydroxyl, alkane and carbonyl groups and the addition of CAL into alkyd paint has caused little shifting and reduction in intensity due to the complexation and cross-linking activity. The lowest weight-loss percentage 
recorded was $3.21 \%$, while the impedance data shows the highest value of polarization resistance $R_{p}$ at $2.57 \times 10^{5} \Omega$ and lowest doublelayer capacitance $\left(C_{d d}\right)$ data at $6.19 \times 10^{-6} \mathrm{~F}$ for coated sample loaded with $0.60 \%$ CAL extract. SEM micrograph and camera images show several coating defects, where CAL extract was seen to form complexation with alkyd resin via cross-linking activity.

\section{Acknowledgements}

The authors would like to thank the Look east policy grant VOT 53168 for the funding, laboratory staff of Faculty of Ocean Engineering Technology and Informatics, Maritime Technology and Physics for their help.

\section{References}

Ahamad, I., \& Quraishi, M. A. (2010). Mebendazole: New and efficient corrosion inhibitor for mild steel in acid medium. Corrosion Science, 52(2), 651-656.

Al-Amiery, A., Kadhum, A., Alobaidy, A. H., Mohamad, A., \& Hoon, P. (2014). Novel corrosion inhibitor for mild steel in HCl. Materials, 7(2), 662-672.

Boshtam, M., Moshtaghian, J., Naderi, G., Asgary, S., \& Nayeri, H. (2011). Antioxidant effects of Citrus aurantifolia (Christm) juice and peel extract on LDL oxidation. Journal of Research in Medical Sciences: The Official Journal of Isfahan University of Medical Sciences, 16(7), 951.

Çolak, Hakan, \& Ercan Karaköse. (2017). Green synthesis and characterization of nanostructured $\mathrm{ZnO}$ thin films using Citrus aurantifolia (lemon) peel extract by spincoating method. Journal of Alloys and Compounds, 690(2017), 658-662.

Dakhil, R. M., Gaaz, T. S., Al-Amiery, A. A., \& Kadhum, A. A. H. (2018). Inhibitive impacts extract of Citrus aurantium leaves of carbon steel in corrosive media. Green Chemistry Letters and Reviews, 11(4), 559566.
Dariva, C. G., \& Galio, A. F. (2014). Corrosion inhibitors-principles, mechanisms and applications. In Developments in corrosion protection. IntechOpen.

Deyab, M. A. (2015). Effect of carbon nanotubes on the corrosion resistance of alkyd coating immersed in sodium chloride solution. Progress in Organic Coatings, 85, 146-150.

Dhoke, S. K., Sinha, T. M., Dutta, P., \& Khanna, A. S. (2008). Formulation and performance study of low molecular weight, alkyd-based waterborne anticorrosive coating on mild steel. Progress in Organic Coatings, 62(2), 183-192.

Dwivedi, D., Lepková, K., \& Becker, T. (2017). Carbon steel corrosion: A review of key surface properties and characterization methods. RSC Advances, 7(8), 4580-4610.

Elba, M. E., Rehim, E. M. A., \& Ashery, R. E. (2018). Progress in organic coating: Synthesis and characterization alkyd resin based on soya bean oil and Gelycrin using Zirconium Octoate as catalyst. Chemical Technology Indian Journal, 13(1), 118.

Haldhar, R., Prasad, D., \& Bhardwaj, N. (2019). Extraction and experimental studies of Citrus aurantifolia as an economical and green corrosion inhibitor for mild steel in acidic media. Journal of Adhesion Science and Technology, 33(11), 1169-1183.

Hassan, K. H., Khadom, A. A., \& Kurshed, N. H. (2016). Citrus aurantium leaves extracts as a sustainable corrosion inhibitor of mild steel in sulfuric acid. South African Journal of Chemical Engineering, 22, 1-5.

Hussin, M. H., Kassim, M. J., Razali, N. N., Dahon, N. H., \& Nasshorudin, D. (2016). The effect of Tinospora crispa extracts as a natural mild steel corrosion inhibitor in $1 \mathrm{M} \mathrm{HCl}$ solution. Arabian Journal of Chemistry, 9, S616-S624.

Instruments, G. (2007). Basics of electrochemical impedance spectroscopy. G. Instruments, Complex impedance in Corrosion, 1-30. 
Loizzo, M. R., Tundis, R., Bonesi, M., Menichini, F., De Luca, D., Colica, C., \& Menichini, F. (2012). Evaluation of Citrus aurantifolia peel and leaves extracts for their chemical composition, antioxidant and anti-cholinesterase activities. Journal of the Science of Food and Agriculture, 92(15), 2960-2967.

Masroor, S., Mobin, M., Alam, M. J., \& Ahmad, S. (2017). The novel iminium surfactant p-benzylidene benzyldodecyl iminium chloride as a corrosion inhibitor for plain carbon steel in $1 \mathrm{M} \mathrm{HCl}$ : Electrochemical and DFT evaluation. RSC Advances, 7(37), 23182-23196.

Mohan, R., \& Joseph, A. (2018). Corrosion protection of mild steel in hydrochloric acid up to $313 \mathrm{~K}$ using propyl benzimidazole: Electroanalytical, adsorption and quantum chemical studies. Egyptian Journal of Petroleum, 27(1), 11-20.

Öhman, M., Persson, D., \& Leygraf, C. (2006). In situ ATR-FTIR studies of the aluminium/ polymer interface upon exposure to water and electrolyte. Progress in organic coatings, 57(1), 78-88.

Rabizadeh, T., \& Asl, S. K. (2019). Casein as a natural protein to inhibit the corrosion of mild steel in $\mathrm{HCl}$ solution. Journal of Molecular Liquids, 276, 694-704.

Rafaie, H. A., Nor, R. M., \& Amin, Y. M. (2015). Magnesium doped $\mathrm{ZnO}$ nanostructures synthesis using citrus aurantifolia extracts: Structural and field electron emission properties. Materials Express, 5(3), 226232.

Samsudin, A. S., Khairul, W. M., \& Isa, M. I. N. (2012). Characterization on the potential of carboxy methylcellulose for application as proton conducting biopolymer electrolytes. Journal of Non-crystalline solids, 358(8), 1104-1112.

Saratha, R., Priya, S. V., \& Thilagavathy, P. (2009). Investigation of Citrus aurantiifolia leaves extract as corrosion inhibitor for mild steel in $1 \mathrm{M} \mathrm{HCl}$. Journal of chemistry, 6(3), 785-795.

Siti, H. N., Kamisah, Y., Iliyani, M. I. N., Mohamed, S., \& Jaarin, K. (2017). Citrus leaf extract reduces blood pressure and vascular damage in repeatedly heated palm oil diet-Induced hypertensive rats. Biomedicine \& Pharmacotherapy, 87, 451460.

Sonnati, Matthieu, Sonia Amigoni, Elisabeth Taffin de Givenchy, Thierry Darmanin, \& Frédéric Guittard. (2012). Investigating the thermorheological properties of conventional and biobased alkyd resins.

Sung, S. J., Kim, T., Park, J., So, S. H., Choi, J., Yang, S. J., \& Park, C. R. (2017). Influence of the physicochemical characteristics of reduced graphene oxides on the gas permeability of the barrier films for organic electronics. Chemical Communications, 53(49), 6573-6576.

Tator, K. B., \& Lanterman, R. (2016, June). Coating deterioration-A mechanistic overview. In CORROSION 2016. NACE International.

Velasco, B. L. H., Arrieta-Baez, D., Sotelo, P. I. C., Méndez-Méndez, J. V., Martínez, B. M. B., \& Gómez-Patiño, M. B. (2017). Comparative studies of cutins from lime (Citrus aurantifolia) and grapefruit (Citrus paradisi) after TFA hydrolysis. Phytochemistry, 144, 78-86.

Verma, C., Sorour, A. A., Ebenso, E. E., \& Quraishi, M. A. (2018). Inhibition performance of three naphthyridine derivatives for mild steel corrosion in $1 \mathrm{M} \mathrm{HCl}$ : Computation and experimental analyses. Results in Physics, 10, 504-511.

Zulkifli, M. F. R., Ghazali, M. S. M., Isa, M. I. N. M., Jusoh, S. M., Yabuki, A., \& Nik, W. M. N. W. (2020). Corrosion resistance evaluation of acrylic coating incorporated with henna leaves extract. Jurnal Kejuruteraan, 32(2), 297-305. 